\title{
$\longrightarrow$ Journal of Electronic Materials Seeks Submissions for Two Topical Collections; TMS Member Receives Named Chair Appointment \\ themagazine
}

member news

Share the good news

about your professional accomplishments!

Contact Kaitlin Calva,

JOM Magazine

Managing Editor,

atkcalva@tms.org.

Please note that only

news submitted by

current TMS members

will be considered.

\section{News on Two Topical Collections for the Journal of} \section{Electronic Materials}

The Journal of Electronic Materials (JEM) is planning a new topical collection, Carbon-Based Materials for Energy

Storage. Article submissions are due by December 31, 2020.

The collection will focus on and highlight recent progress on carbon-based materials for electrochemical energy storage and present a broad overview on new synthetic methods as well as novel characterization techniques revealing physiochemical mechanisms. It also aims to address how carbon materials are playing important roles in electrochemical storage systems as either active electrodes or conductive skeletons/layers.

Topics for this collection will include, but are not limited to:

- Carbon-based materials for electrochemical energy storage

- Synthesis methods for carbon materials for energy storage

- Characterization techniques for carbon-based energy storage

- Batteries and supercapacitors

- Modeling, simulation, and computation of carbon-based electrode materials

To submit your work, go to www .editorialmanager.com/jems and select article type "2020 Carbon Energy Storage." Author instructions and additional journal details are available at www.springer .com/11664.

The guest editors of this topical collection are: Xinhui Xia, Zhejiang University; Hui Xia, Nanjing University of Science and Technology; Faxiang Qin, Zhejiang University; and Xihong Lu, Sun Yat-Sen University.

Additionally, the submission deadline for JEM's previously announced special topical collection, Progress and Challenges with Stability, Sustainability, Toxicity, and Scalability of Perovskite Materials and Devices, has been extended

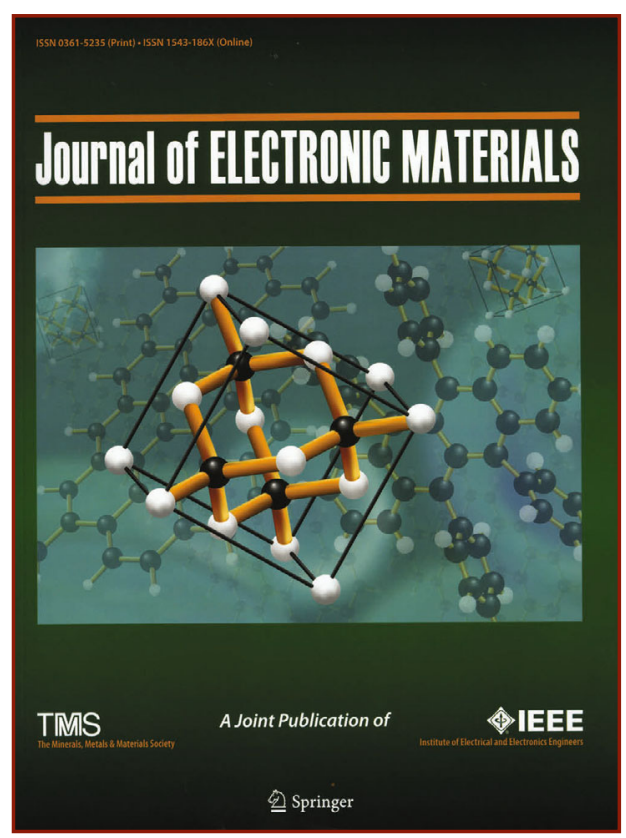

to October 1, 2020. While all perovskiterelated contributions are welcome, the following areas are of special interest for this collection:

- Susceptibility to ambient environment resulting from insufficient encapsulation

- Material chemical stability due to inhibition of light-induced decomposition

- Energy losses in the bulk of the material, as well as the surface and interfaces

- Free exciton trapping and luminescence quenching

- Control of nucleation and rapid crystallization by modulating growth conditions

- New insight on structure-propertyperformance relationships

- Theoretical modelling, first-principles calculations, and machine learning discovery

Articles for this collection can also be submitted at www.editorialmanager.com/ jems. Once there, select article type "2020 Perovskite Materials and Devices.” 


\section{Andrea Hodge Begins USC Department Chair Appointment}

Andrea Hodge has been appointed to a three-year term as the chair of the Mork Family Department of Chemical Engineering and Materials Science at the University of Southern California (USC). She is currently the vice provost for undergraduate programs at USC and the Arthur B. Freeman Professor of Chemical Engineering and Materials Science and Aerospace and Mechanical Engineering, in addition to serving as the co-director for the Core Center of Excellence in Nano Imaging. Her new role as department chair will begin on August 16, 2020.

A TMS member since 1998, Hodge is a recipient of the 2020 Julia and Johannes Weertman Educator Award "for her outstanding contributions to educating and mentoring students in materials science and engineering." In 2004, she received the Materials Processing \& Manufacturing Division Young Leaders Professional Development.

Outside of TMS, several prestigious research awards have been conferred upon Hodge, including the National Science Foundation's CAREER Award, an Office of Naval Research (ONR) Young Investigator Program Award, and a Defense Advanced Research Projects Agency (DARPA) Young Faculty Award.

\section{In Memoriam: Kuang-Tsan “Kenneth” Chiang \& Erhard Hornbogen}

TMS extends its condolences to the family, friends, and colleagues of the following members:

Kuang-Tsan "Kenneth" Chiang passed away on May 7, 2020, at the age of 69. A senior TMS member who joined in 1980, Chiang had worked as a materials science engineer and specialized in powder metallurgy and physical vapor deposition. Most recently, he worked as a senior research scientist at the Southwest Research Institute. After retiring, Chiang taught physics at Northwest Vista College. Throughout his career, he held positions at RCA, Lockheed Martin, the Rocketdyne Division of Rockwell International (which later became Boeing Rocketdyne), and Aerojet.

Chiang earned his bachelor's degree in physics from National Tsing Hua University in Taiwan. After serving as a second lieutenant in the army, he came to the United States in 1974 to earn his doctorate in from the University of Pittsburgh's Department of Physics and Astronomy. He also earned his M.S. in the management of technology from the University of Texas at San Antonio. In 2011, he became one of the first people from National Tsing Hua University or from Taiwan to be named an Associate Fellow of the American Institute of Aeronautics and Astronautics.
Erhard Hornbogen passed away at the age of 90 on April 16, 2020. A longtime TMS member, he is known for his research on understanding the design of superalloys, which provided the basis for the development of modern aircraft engines. Hornbogen earned his Ph.D. from the University of Clausthal in 1957, where his work as a research associate led to his 1956 discovery of the shape memory effect in $\mathrm{Cu}$-based alloys.

His research career included positions at the University of Oxford; the Edgar C. Bain Laboratory for Fundamental Research (a U.S. Steel Corporation Institute); the Max Planck Institute for Metals Research; the Norwegian Central Institute for Applied Research; and the University of Goettingen. Additionally, Hornbogen participated in many extended research stays across the globe, including in the United States, France, and China. Hornbogen founded the Institue for Materials Research at Ruhr-University Bochum, serving as chair for Materials Science from 1968 until 1995.

Among many honors awarded to him over the years, Hornbogen received the 1979 TMS Institute of Metals/Robert Franklin Mehl Award.

JOM thanks Gunther Eggeler, Herbert Gleiter, and Easo George for thier contributions to Hornbogen's obituary.

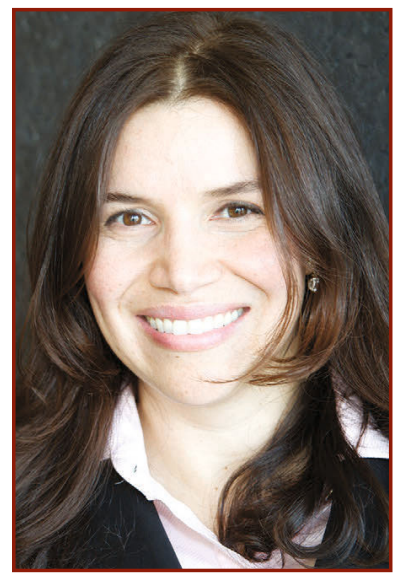

Andrea Hodge

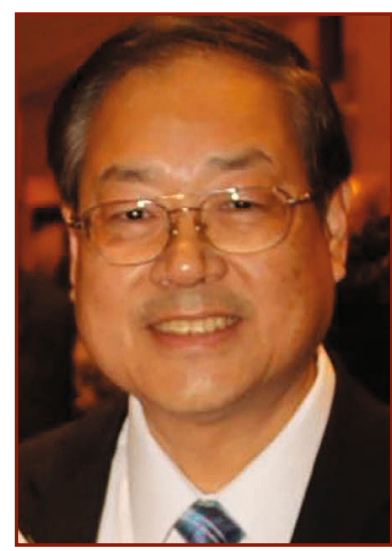

Kuang-Tsan “Kenneth" Chiang

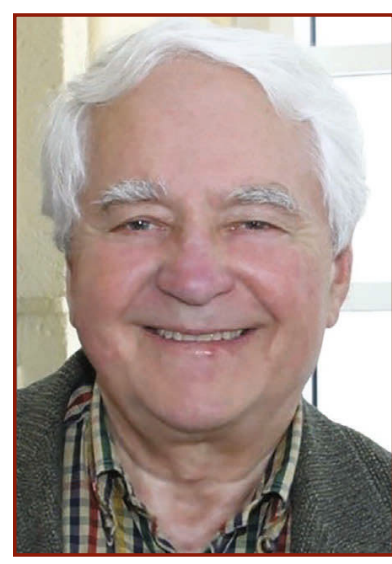

Erhard Hornbogen 